intelligence, on colour-blindness, and on instituting university teaching in medical and industrial psy. chology. His son has been appointed by the University to succeed him in his professorship.

Industrial Relations and the Cost of Living Index A Broadsheet "Wages and the Cost of Living Index" (No. 220) issued by Political and Economic Planning gives a useful brief review of the cost of living index itself and of the wage systems in the building and civil engineering, railways, iron and steel, coal and cotton industries and the Civil Service in Great Britain. The broadsheet forms part of a report on industrial relations which $\mathrm{P} \mathrm{E} \mathrm{P} \mathrm{is} \mathrm{prepar-}$ ing, and does something to meet the need for a study of wages and other aspects of industrial relations which such innovations as 'pay-as-you-earn' have intensified. In addition to its descriptive part, the broadsheet includes the general conclusion, first, that if wage policy were sufficiently well co-ordinated between workers and employers and between different industries, it could be arranged that wages should not fall as much as prices during the down-swing, and that in return they should not be pushed up so much when prices are once more rising. Such a policy has been put into practice in Sweden with results that open up a vista of possible 'trade-cycle bargaining', under which the application of sliding scales as we know them would be inappropriate. From the workers' point of view it would be wrong to peg wages to the cost of living and thus stabilize real wages when their productivity is increasing and prices falling, for this would mean that their share in the product of their labour would be declining. One may expect that if post-war employment succeeds in producing a steadily rising national income, workers in most industries will prefer to rely on their bargaining power rather than on automatic scales. Part of the dynamic of a full employment policy must be the general striving for an uninterrupted rise in the standard of living, and therefore in real wages.

Where the workers in an industry have little expectation of increasing their standard of living, they may decide that the sliding scale will at least help to maintain their real wages. What is good for one industry, however, may not suit another; and the different sliding-scale schemes have different effects on the internal wage structure of the industries concerned. Cost of living calculations will remain of the greatest importance whether or not an automatic sliding scale is used. The minimum or subsistence allowance, in terms of money, for example, fails of its purpose unless it is adjusted to cover changes in the prices of the goods needed for subsistence, and for this purpose the sliding-scale method will continue to have an obvious justification. It would seem, however, that the avowed purpose of the index, to estimate changes in "the cost of maintaining unchanged the pre-war (i.e., pre-1914) standard of living of the working-classes" has not much relevance to present-day requirements, and that separate indexes are required for various income groups and for different localities. If authoritative indexes of this kind could be provided, much that is at present contentious guesswork in wage negotiations would be based on measurement and calculation, and the application of an accurate series of cost of living indexes would not be confined to wages but should form an essential part of national statistics.

\section{Sunspots and Human Affairs}

Two papers by W. G. Bowerman (Pop. Astron., 52, March, April, May, 1944) discuss the rather indefinite subject of the relations between sunspots and terrestrial conditions. The first illustrates a close parallelism between sunspot numbers and the total mortgage loans on residential property in the United States. This held during 1923-38 but broke down in 1939 , presumably owing to the disturbance caused by the War. The second and longer paper describes in a 'popular' manner the quasi-periodic nature of outbreaks of sunspots and a good deal of recent American literature on relations between sunspot numbers and extremes of temperature and precipitation, as well as such indirect effects as industrial activity, forest fires and outbreaks of tropical diseases. The author accepts the views of Ellsworth Huntington and C. A. Mills that the major economic and cultural cycles of historical times result from long-period. oscillations of solar activity, acting through average temperature, which in turn controls both the spread of disease organisms and the power of man to resist or cope with them. Within the 11-year cycle there is a 'sharp upthrust' of temperature near sunspot minimum, but the relations are complicated by volcanic eruptions.

The whole subject of the reaction of man with his environment is of considerable interest and importance to students of human affairs; but it is far too complex for superficial or partial studies to have any value. For example, the author refers casually to the effect of air-conditioning of hospitals in counteracting climatic control of disease; but he overlooks Major Markham's hypothesis that the poleward march of civilization is a function of the efficiency of house-warming. There is room here for a new system of philosophy, but the first necessity is to verify and comprehend the facts.

\section{Structure and Classification of Bees}

The Bulletin of the American Museum of Natural History, 82, 1944, contains a very comprehensive memoir on the above subject, written by C. D. Michener, an assistant curator of the Museum. The method which the author has adopted is to make a detailed study of the morphology of a single species of bee, for example, Anthophora edwardsii, and then to compare numerous other bees with this species. Finally, with these comparisons as a basis, the author gives an account of the interrelationships of the various groups of bees followed by a general scheme of classification. The latter deals with all groupings, from families to genera, represented in America north of Mexico. The memoir is one intended for the specialist on the order Hymenoptera. The anatomical section is concerned with external organs and parts only; the internal organs and musculature being outside the scope of the work. A certain number of new terms are used including the expressions mesosoma and metasoma for the regions commonly referred to as thorax and abdomen respectively. Six families of bees are recognized. The Colletidæ and Halictidæ are the two oldest groups. The next in order of antiquity are considered to be the Andrenidæe and Apidæ followed doubtfully by the Megachilidæ. The last family-the Melittidæ-is too imperfectly known to suggest its position in the series. The largest family is the Apidæ which is held to include a large number of bees usually considered to be outside its limits. The author mentions that cer- 
tain of these have often been placed in separate families largely on the basis of the presence or absence of the pygidial plate. This character is regarded as being unreliable since it is often lost in very different bees.

\section{Glossary of Communicable Diseases}

A LIST of terms in the main European languages and in Latin denoting the various communicable diseases has recently been published ("Lexique Polyglotte des Maladies Contagieuses" (Polyglot Glossary of Communicable Diseases). By Dr. Yves Biraud. (London: Allen and Unwin: League of Nations Publications Dept., 1944. Pp. 354. 4s.). The author states in his introduction that circumstances did not allow of the sending of questionnaires to medical authorities of the various countries or of submitting proofs of the Glossary to them. This is quite obvious, and anyone looking for an accurate guide of this type will be well advised to await the appearance of a heavily amended second edition.

The term communicable is very widely interpreted, and the lists include appendicitis and Ludwig's angina, osteomyelitis and pemphigus of unspecified type. Catarrhal jaundice is listed twice, although this probably erroneous term for infective hepatitis is now nearly obsolete. Herpes zoster and herpes febrilis are given as synonyms. Chancroid, the most specific and commonly accepted name for soft chancre, does not appear. In the section on syphilis the terms for various manifestations do not correspond in the columns for the different languages.

\section{Sulphadiazine Treatment of Meningitis}

According to the U.S. Office of the Surgeon General, a saving of 90 out of 100 soldiers from death by meningitis has been achieved by sulphadiazine. The death-rate from meningitis in the U.S. Army in the present War is less than 3 per cent, whereas it was $\mathbf{9 3 . 2}$ per cent in the Revolutionary and Civil Wars and $39 \cdot 2$ per cent in the War of 1914-18. According to the U.S. Army Commission on Meningitis, as little as two grams of sulphadiazine will banish the germs from the nose and throat of most persons for a period of several weeks.

\section{Pole Treatment}

IN an article on ground-line treatment of standing poles (Bell Lab. Rec., 22, No. 11; July 1944), C. H. Amadon discusses the preservative method developed by Bell System engineers. External deterioration of an untreated pole in service begins in the ground section with infection by wood-destroying fungi which, once established, continue there unless adverse conditions are imposed, as for example, by the application of a suitable wood preservative. Two general classes of preservatives might be used for ground-line treatment, (1) oily materials such as creosote, and (2) water solutions of toxic salts such as zinc chloride and sodium fluoride. Sodium fluoride is particularly good for penetrating the heartwood of cedar and chestnut timbers, but it is not permanent. Creosote or creosote and coal tar, although not as penetrating as the water-soluble salt, is as lasting as any preservative known.

Beginning in 1935, Bell Laboratories engineers treated experimentally a total of 428 poles and posts with coal-tar creosote and other coal tar products, sodium fluoride, sodium silico-fluoride, and proprietary pastes and solutions containing preservative compounds. Periodic examinations and accumulated evidence during five years showed that treatment at the ground line with sodium fluoride and a mixture of creosote and coal tar is highly effective. This treatment effectively reduces the rate of deterioration of poles in line, and their service life (ground line condition) will be increased by about six years. This is sufficient to justify the costs involved, but an additional saving accrues from the possibility of placing pole line inspection on a six-year instead of the usual three-year cycle. The cumulative result of the ground-line treatment is a reduction in labour and expense of pole line maintenance-inspection and in the need for new poles.

\section{Paint Drying by Radiant Heat}

Imperial Chemical INdUstries, LTd., has recently issued a handy twenty-page booklet on this subject for the purpose of providing information on the properties of radiant heat, to indicate how these apply to the different types of plant now available for stoving paints, and how the qualities of the paints used are affected by the process. The chapter contents of the booklet relate to heat transfer, radiant heat, methods of drying paint, radiant heating equipment, radiant heating technique, and paints and radiant heat. Copies of the booklet may be obtained, free of charge, from I.C.I., Ltd., Belmont, The Ridgeway, Mill Hill, London, N.W.7.

\section{Seismology in Chins}

IT is learned (Earthq' ake Notes, 15, Nos. 3 and 4 ; 1944) that the active recording of earthquakes is being continued in China. The Japanese invasion caused the National Geological Survey of China to change its headquarters to Chungking. The seismograph station at Chiufeng had to be abandoned. Dr. $\mathrm{S}$. P. Lee has re-established the seismological work at Pehpei near Chungking. He has built a onecomponent instrument (north-south), which is being operated with a period of $4.5 \mathrm{sec}$. Recording began in October 1943.

\section{University of Bristol}

THE following appointments in the University of Bristol have recently been announced:

Dr. J. E. Harris, to be professor of zoology in succession to Prof. C. M. Yonge, who has been appointed Regius professor of zoology in the University of Glasgow.

Dr. Wilson Baker, to be Alfred Copper Pass professor of chemistry in succession to Prof. E. L. Hirst, who has been appointed professor of chemistry in the University of Manchester.

Dr. A. G. Pugsley, to be professor of civil engineering in succession to Prof. J. F. Baker, who is now professor of mechanical sciences in the University of Cambridge.

Erratum.-Sachchidananda Banerjee writes, in connexion with his communication "Effect of Vitamin $\mathrm{C}$ on the Adrenaline Content of the Adrenal Glands of Guinea Pigs" in Nature of April 29, p. 526, the phrase "The adrenal glands were extracted with trichloracetic acid for adrenaline and ascorbic acid according to the method of Rees"' should read: "The adrenal glands were extracted with trichloracetic acid for adrenaline and ascorbic acid according to the method of Barker and Marrian ${ }^{2}$. The adrenaline was estimated chemically by the method of Rees". 